\title{
Critical Realism in Information Systems Research
}

\author{
John Mingers \\ Kent Business School, University of Kent, \\ Canterbury, Kent, CT2 7NZ UNITED KINGDOM \{j.mingers@kent.ac.uk\}
}

\author{
Alistair Mutch \\ Nottingham Business School, Nottingham Trent University, Burton Street, \\ Nottingham NG1 4BU UNITED KINGDOM \{Alistair.mutch@ntu.ac.uk\} \\ Leslie Willcocks \\ London School of Economics and Political Science, Houghton Street, \\ London WC2A 2AE UNITED KINGDOM \{l.p.willcocks@lse.ac.uk\}
}

\section{Introduction}

There has been growing interest in a range of disciplines (Ackroyd and Fleetwood 2000; Danermark et al. 2002; Fleetwood 1999; Fleetwood and Ackroyd 2004), not least information systems (Dobson 2001; Longshore Smith 2006; Mingers 2004b; Mutch 2010b; Volkoff et al. 2007; Wynn and Williams 2012) in ideas derived from the philosophical tradition of critical realism. Critical realism offers exciting prospects in shifting attention toward the real problems that we face and their underlying causes, and away from a focus on data and methods of analysis. As such, it offers a robust framework for the use of a variety of methods in order to gain a better understanding of the meaning and significance of information systems in the contemporary world.

Although the term critical realism has been used in a number of different traditions, we are primarily concerned with that developed from the foundational work of Roy Bhaskar in the philosophy of science, later extended in the social arena by authors such as Archer and Sayer (Archer et al. 1998; Bhaskar 1978, 1979; Mingers 2004b; Sayer 2000). In this tradition, the benefits of CR are seen as:

- CR defends a strongly realist ontology that there is an existing, causally efficacious, world independent of our knowledge. It defends this against both classical positi- vism that would reduce the world to that which can be empirically observed and measured, and the various forms of constructivism that would reduce the world to our human knowledge of it. Hence it is realist.

- CR recognizes that our access to this world is in fact limited and always mediated by our perceptual and theoretical lenses. It accepts epistemic relativity (that knowledge is always local and historical), but not judgmental relativity (that all viewpoints must be equally valid). Hence it is critical in a Kantian sense.

- CR accepts the existence of different types of objects of knowledge - physical, social, and conceptual—which have different ontological and epistemological characteristics. They therefore require a range of different research methods and methodologies to access them. Since a particular object of research may well have different characteristics, it is likely that a mixed-method research strategy (i.e., a variety of methods in the same research study) will be necessary and CR supports this.

In this introduction, we will first introduce the basic concepts of critical realism as a philosophy of science, and then discuss its extensions into the social realm, before finally introducing the excellent papers that are included in this issue. 


\section{Critical Realism: Basic Concepts}

Critical realism (CR) developed initially by way of arguments against both the empiricist view of science as embodied in positivism (Bhaskar 1978), and the idealist view of (social) science as embodied in constructivism or interpretivism (Bhaskar 1979). Later, it also engaged with postmodernism and other irrealist viewpoints (Bhaskar 1986, 1989). Through this immanent critique of alternative positions it developed its own approach, which was most fully articulated within a dialectical perspective (Bhaskar 1993).

The starting point was to argue, specifically against empiricism and positivism, that science is not just about recording constant conjunctions of observable events, as the Humean view of causation embedded in positivism would have it, but is about objects, entities and structures that exist (even though perhaps unobservable) and generate the events that we observe. The form of the argument is a transcendental one. That is, it begins with some accepted phenomenon and asks what the world must be like for this to occur. In this case, what is accepted by both empiricism and many forms of idealism is that we do have perceptual experience of the world, and that science is carried out through experimental activity in which scientists bring about particular outcomes. The argument is that neither empiricism nor idealism can successfully explain these occurrences and that they necessitate some form of realist ontology. Essentially, there must be some intransitive domain of object and events, independent of our perceptions of them, which can indeed become objects of our knowledge.

The argument can be expressed in terms of the mistake that both empiricism and strong forms of idealism or constructivism make - that is, the epistemic fallacy. The essential mistake is in reducing the ontological domain of existence to the epistemological domain of knowledge: statements about being are translated into ones about our (human) knowledge or experience of being. For the empiricist, that which cannot be perceived cannot be. For the conventionalist, limitations of our knowledge of being are taken to be limitations on being itself. In contrast, the realist asserts the primacy of ontology: the world would exist whether or not humans did. The empiricist identification of causal laws with empirical regularities thus involves a double reduction - that of laws to events and events to experiences of those events.

But what is it that causes or generates events given both the regularities that can be established in experiments, and the common absence of regularity outside? Equally, how can we assure ourselves that event regularities are based on necessary connections rather than simply coincidence? The answer is that there must be enduring entities, physical (e.g., atoms or organisms), social (e.g., the market or the family) or conceptual (e.g., categories or ideas), observable or not, that have powers or tendencies to act in particular ways. It is the continual operation and interaction of these mechanisms that generates the flux of events. Entities or mechanisms may have powers without exercising them at a particular time (it may need an experiment or particular context to trigger them), and powers may be exercised but not become manifest in events because of the countervailing operation of some other generative mechanism. The heart of this argument is that of a causal criterion for existence rather than a perceptual one. In other words, for an empiricist, only that which can be perceived can exist, whereas for a realist, having a causal effect on the world implies existence, regardless of perceptability. This view of causal mechanisms is at the heart of critical realism and, independently, is also becoming dominant within mainstream philosophy of science (Illari and Williamson 2011).

For Bhaskar, reality is both intransitive (existing independently of humans) and stratified (Archer 1998, p. 41). The first form of stratification is between mechanisms, the events that they generate, and the subset of events that are actually experienced. These are known as the domains of the real, the actual, and the empirical. The real contains mechanisms, events, and experiences (i.e., the whole of reality); the actual consists of events that do (or perhaps do not) occur and includes the empirical, those events that are observed or experienced. These distinctions arise from the transcendental arguments above, namely, that we should not reduce all events to only those that are observed, and we should not reduce enduring causal mechanisms to events.

A second form of stratification is within the realm of objects themselves (Archer 1998, p. 66), where causal powers at one level (e.g., chemical reactions) can be seen as generated by those of a lower level (atomic valency). One strata is emergent from another (what Bhaskar terms "emergent powers materialism"). The picture of the real is thus one of a complex interaction between dynamic, open, stratified systems, both material and non-material, where particular structures give rise to certain causal powers, tendencies, or ways of acting, often called by Bhaskar (1979, p. 170) "generative mechanisms." The interaction of these generative mechanisms, where one often counterbalances another, generates the presence or absence of actual events.

Having established the intransitive objects of knowledge, we must recognize that the production of knowledge is very much the work of humans, and occurs in what we could call the transitive dimension (Bhaskar 1989, p. 18). Acknowledging the work of sociologists, the practice of science is a social process drawing on existing theories, results, anomalies, and conjectures (the transitive objects of knowledge) to generate 
improved knowledge of science's intransitive objects. This distinction allows us to admit the epistemic relativity of science, the fact that knowledge is always historically and socially located, without losing the ontological dimension. We should also note that such epistemic relativity does not imply a corresponding judgmental relativity (i.e., that all views are equally valid and that there are no rational grounds for choosing between them).

We can now describe the critical realist scientific methodology, what Bhaskar calls retroduction (this is essentially the same as "abduction," as developed by C. S. Peirce (19311958 , ss. 5.145) in contrast to induction and deduction). We take some unexplained phenomenon that is of interest to us and propose hypothetical mechanisms that, if they existed, would generate or cause that which is to be explained. So, we move from experiences in the empirical domain to possible structures or mechanisms in the real domain. This is the essential methodological step in CR studies: to move from descriptions of empirical events or regularities to potential causal mechanisms, of a variety of kinds, some of which may be nonphysical and nonobservable, the interaction of which could potentially have generated the events. Such hypotheses do not, of course, prove that the mechanisms do in fact exist. And, we may have competing explanations proposed, so there is then a further stage within the methodology in which more research has to be carried out to try and eliminate some of the explanations and perhaps support others.

One could ask: How do we know that such hypothetical mechanisms actually do exist rather than being merely interesting ideas? At one level, the answer is that we can never know for certain, since CR accepts that knowledge is always fallible. More practically, however, the intransitivity of real structures means that they will always have the potential for effects that go beyond us (i.e., are out of our control), and the approach means that we should aim to eliminate alternative explanations by testing in some way for their potential effects. This methodology is known as DREI: describe the events of interest; retroduce explanatory mechanisms; eliminate false hypotheses; identify the correct mechanisms. In terms of research methods, CR is eclectic. Because the underlying structures may have a variety of forms - material, social, and cognitive - we need a variety of epistemological methods to access them. Traditionally, CR has been somewhat hostile to statistical methods, especially in social science, on the grounds that they assume a degree of closure that is seldom present (Olsen and Morgan 2005) but there is now a greater acceptance of their value (Mingers 2006; Pratschke 2003). CR also licenses and underpins the idea of combining different research methods, what is called mixed-method research or multimethodology (Mingers 2001; Venkatesh et al. 2013). Wynn and Williams (2012) have pro- duced a valuable description of principles for critical realist case study research.

We have so far discussed the ontological commitments of CR, and we now move to a more epistemological argument: that social science is essentially similar to natural science in its realist character, albeit with modifications to reflect the particular nature of the social world. We can begin by asking what would rule out a realist approach to social science. The answer is presumably that there are no intransitive objects for social science to investigate. Such an argument could come from the extreme constructivists (or superidealists, as Bhaskar calls them) who would also apply it to the natural world, or from those such as constructivists or individualists who would argue for the distinctive nature of social phenomena as being intrinsically meaningful and not existing independently of the mental processes of social actors.

Bhaskar's (1979, Ch. 2) primary argument is against methodological individualists who maintain that all explanations can be couched in terms of an individual's beliefs and actions. The first refutation concerns emergent properties: there are attributes that can be applied to people that concern physical features, height, weight; there are attributes that we share with other animals such as pain or hunger; but there are many attributes, essentially human ones, that are unavoidably social, for example bachelor, banker, or nun. These are only intelligible within the context of a social institution or practice. The second argument is that many activities we undertake, most obviously, perhaps, language, must already exist and be available for people to learn and then use. As Wittgenstein (1958) argued, there can be no such thing as a private language; every time anyone has a conversation, uses a credit card, or waits for a train, they are assuming the existence of a structured, intransitive domain of resources, concepts, practices, and relationships. The successful occurrence of social activities warrants the existence of causally efficacious, although unobservable, social structures.

Bhaskar does accept, however, that social phenomena are inherently different from material phenomena and that this does put limits on the nature of social science (see Bhaskar 1979). Social science is, however, still driven by the existence of an intransitive domain of generative mechanisms; a recognition of the epistemic (but not judgmental) relativity of knowledge; and a retroductive methodology that explains events by hypothesizing causal mechanisms.

\section{Social Theory Within Critical Realism}

Building on these conceptual foundations, a number of approaches to the social world have been developed. Prominent 
among them, and figuring in contributions to this special issue, are the work of Margaret Archer (1995) in sociology and Tony Lawson (1997) in economics. It is important to note that both started from a critical engagement with existing perspectives in their respective domains, an engagement which saw them turn to critical realism in its role as an "under-laborer" to help them develop their own approaches. This is important because it emphasizes that critical realism both requires and facilitates detailed engagement with other traditions, as illustrated by the connections that Allen et al. (2013) draw with activity theory in their contribution. It also points to on-going debate between those that share the basic ontological commitments outlined in the previous section. Bhaskar (1979) himself developed an application of his ideas to the social world which he termed the transformational model of social action (TMSA). It is worth noting that aspects of this inform Giddens' (1984) arguments in developing his widely influential structuration theory (Mingers 2004a). The TMSA has been broadly endorsed by Lawson and others, such as Faulkner and Runde (2013) who use it as a backdrop to their conceptual explorations of materiality in this issue. By contrast, Archer has been more critical and has developed her approach over an extensive series of books (Archer 1988, 1995, 2000, 2003, 2007, 2012). As it is developed at such length and is employed by a number of contributors to this special issue, Archer's approach is worth briefly exploring a little further.

Archer's work is closely associated with her contribution to the structure-agency debate. The particular relevance to the IS domain is that she develops her ideas through an extensive critique of the work of Giddens, whose structuration theory has been widely used as a guiding theory, notably in the work of Orlikowski (2000). Archer suggest that Giddens' formulation of structures as "memory traces" conflates agency and structure and does not allow for a consideration of their development and relationship over time. We can trace the continuing influence of this tendency in the ideas of sociomateriality, where the social and the material are seen as constitutively entangled (Orlikowski and Scott 2008). By contrast, Archer's ideas, with their notion of "analytical dualism," enable us to refresh traditions such as sociotechnical systems that examine the interplay between the social and the material over time (Leonardi and Barley 2008). Archer's work, however, is about more than the formulation of agency as taking place always in conditions which predate action and which shape the opportunities available. Her more recent work has focused on the nature of reflexivity. Using the notion of the "internal conversation," by which humans monitor the on-going status of their central concerns, she argues that all humans are reflexive, but that they deploy different modes of reflexivity. Such modes, she argues, are linked to particular combinations of structural and cultural moments, both in time and space. Dobson et al. (2013) use these ideas productively to look at the fate of ICT developments in rural Australia. There is much to be done to develop these ideas, development which will happen as the ideas are put into practice, but Archer's work provides a rich seam of concepts which could help us better understand questions of IS use.

Such use is not without its challenges. A key injunction from Archer is that we need to develop "analytical narratives" in which the interplay of agency, structure and culture is examined over time. Njihia and Merali (2013) essay such a narrative in their account of ICT4D in Kenya, but this is a difficult task within the confines of a journal article. Archer's (1979) own early empirical work on the development of educational systems covers a 300 year period in some 800 pages! That points to another challenge, in that her ideas are developed on the terrain of social theory, covering often large sweeps of time. Relating this to the examination of contemporary organizations and their use of IS can seem daunting. Archer has relatively little to say about either, but theorists such as Elder-Vass (2008) in the same tradition and those working in organization theory are starting to translate the ideas to a more usable scale (Ackroyd and Fleetwood 2000). By the same token, the work of both Lawson and Archer proceeds by way of the critique of existing positions and the development of responses at the level of general and abstract theory. This often seems distant from the concerns of those examining more situated action and a key challenge is showing how these ideas can be applied to aid concrete research. This special issue is one step in progressing this agenda, and we reflect on some of the methodological challenges that this posed in the next section. However, before doing this, it is worth outlining briefly some opportunities for taking some of the ideas thrown out by Archer forward.

In arguing for the centrality of The Reflexive Imperative in Late Modernity, Archer suggests that

From the 1980s onwards, the synergy between multi-national production and information technology resulted in unprecedented morphogenesis, whose generative mechanism is for variety to spawn more variety (2012, p. 64).

This is surely a set of claims which are the central terrain of scholars in our field. One way in which we can contribute to this debate is by testing the strength of such claims, which rest on a limited engagement with the detail of organizational research. One of the interesting tensions is that Archer's argument for the centrality of reflexivity in contemporary conditions tends to downplay both routine action and tacit forms of knowing, whereas a considerable volume of work on 
organizations and IS stresses the centrality of both (Mutch 2010a). Archer's claims might cause us to reassess these positions. It also might suggest the need for more focus on how the systems we study have changed the ways in which actors within organizations use information. This is challenging, because it falls at the intersection of a number of disciplinary domains. It also suggests that more of our work ought to be on the use of systems over time, as opposed to looking at how systems are implemented. Although we recognize the problems associated with enterprise systems, it remains the case that they, however imperfectly, are central to the activities of multinational organizations and, one assumes, to the way in which those who work in them use the information they supply to carry out their work. Whether such systems shift the mode of reflexivity that is deployed, perhaps by demanding a more systemic and abstract form of reasoning, and whether such shifts are widespread, are important questions that could, in turn feed into these broader debates at the level of social theory.

\section{Themes in the Special Issue: Theory Building, Research Methods, Applications}

This special issue attracted a range of contributions working within and across the boundaries of critical realist thinking and methods. While most papers had elements of all three contributions - theory building, methods, and applications of $\mathrm{CR}$ - authors did tend to prioritize in which area they were going to make their primary intellectual and research effort.

\section{Theory Building}

Two papers - those by Faulkner and Runde and by Volkoff and Strong - focus primarily on theory development, while a third - that by Allen, Brown, Karanasios, and Normancompares and relates critical realist concepts with activity theory and provides demonstrations of theories in action.

In "Technological Objects, Social Positions, and the Transformational Model of Social Activity," Faulkner and Runde identify a gap in IS-related applications of critical realism. The lack of a systematic theory of the nature, position and identity of technological objects within the TMSA leads them to lay tracks down here, with particular attention to a category particularly key for modern information systems: nonmaterial technological objects. Accepting the TMSA as a "highly generalized but... descriptively accurate image of how society is organized, reproduced, and transformed" (p. 803), their important contribution here is to elaborate a theory of the nature and identity of technological objects and integrate this theory within the TMSA. The theory itself applies to material as well as nonmaterial technical objects. Briefly stated, they suggest that an object possesses a particular technical identity within a community if (1) it has assigned to it the function associated with that technical identity and (2) its structure is such that it is generally able to perform that function. The paper then, valuably, imports the theory into the TMSA. How this is done is a key contribution of the paper.

In "Critical Realism and Affordances: Theorizing ITAssociated Organizational Change Processes," Volkoff and Strong provide theory development in developing and operationalizing critical realism's concept of generative mechanism for an IS context. Using Gibson's affordance theory from evolutionary psychology, Volkoff and Strong show how affordances are a specific form of generative mechanism and that "affordances are the generative mechanisms we need to specify" (p. 819). For these authors, affordance refers to what is offered, provided, or furnished to someone or something by an object. An affordance exists at what critical realists refer to as the domain of the real. Their contribution here is to provide a consistent use of the concept and a clear ontology. Their subsequent contribution is to provide to CR and generative mechanisms the opportunity for more fine-grained explanations of causality, through the development of middle range theory using the concept of affordance. This theory contribution is illustrated by reanalyzing two published cases involving an enterprise system and a custom-built software system. Volkoff and Strong provide a critical realist lens to the cases, identifying across them 19 affordances, and developing the image of affordances as "a thick bundle of interacting strands" (p. 830). It is a highly useful demonstration of how generative mechanisms, informed by affordance theory, can be operationalized in IS research, and also rescues the critical realist underpinnings of the original concept of affordance.

Allen, Brown, Karanasios, and Norman also make a contribution to theory. Their paper is titled "How Should Technology-Mediated Organizational Change Be Explained? A Comparison of the Contributions of Critical Realism and Activity Theory." They argue that critical realism and activity theory can complement one another in forging a "philosophically coherent yet practically attuned materialist framework for understanding IS and the way it supports and transforms work activity" (p. 836). One strong argument the authors make is that activity theory addresses some weakness in CR they identify, particularly in Archer's (1995) morphogenetic approach. They focus specifically on inscription and social and cultural relations in technology. Activity theory as espoused by Ilyenkov (1977) is shown to foreground as essential certain aspects neglected until recently within critical realism, namely semiotics and the mediation of subject and object by technology. The paper also offers two cases of 
technology-mediated organizational change concerning paramedic treatment of heart attack patients and ambulance dispatch activity. The authors provide a detailed account of the processes of change through tensions and contradictions in activity systems, and also introduce the concept of congruencies involving temporary stabilization. By building further on CR-related insights on the inscription of social and cultural relations within technology, they show how the organizational performance management agenda is mediated through IS operationalization in ways that affect the power structure, as well as the efficiency of the organization.

\section{Methods and Applications}

In "Methodological Implications of Critical Realism for Mixed-Methods Research," Zachariadis, Scott, and Barrett examine key CR ideas on causation, validity, and generalizability, and illustrate how these shape the logic of inference in the research process through retroduction. They make a major contribution in using mixed-methods research within a critical realist framework. As they point out, the methodological implications of CR for mixed methods research have been largely unexplored. They usefully explore what happens when working within CR's stratified ontology and focusing on underlying mechanisms, and demonstrate that this refocusing leads to a different (from conventional) understanding of concepts of reliability, validity, and inference quality. In designing mixed-methods research, they point out that the role of quantitative methods within CR is largely descriptive since generalizations and correlations between variables alone cannot uncover evidence regarding causal mechanisms that generate actual events observed, or predict future incidents. Qualitative methods within CR have a more profound role, as they are more capable of describing a phenomenon, constructing propositions, and identifying structured interactions between complex mechanisms. At the same time, for these authors, CR does not commit to a single type of research. CR's critical methodological pluralism is grounded on its ontological and epistemological assumptions, thus preserving a strong link between meta-theory and method. As well as this important theoretical contribution to developing critical realist-informed methods, the authors also contribute a strong demonstration of the applicability of their thinking in a case study of the effect of SWIFT adoption on bank performance. This illustrates how the logic of retroduction can guide a dynamic interplay between methods involving constant comparison. The mixed methods approach enabled moves between situated narrative and statistical descriptions of populations in order to uncover generative mechanisms and make robust meta-inferences.

Three other papers are relatively more straightforward, although imaginative and insightful applications of morpho- genentic analysis and CR-informed methods, particularly leveraging the concept of generative mechanisms. In "The Broader Context for ICT4D Projects: A Morphogenetic Analysis," Njihia and Merali demonstrate the power of Archer's morphogenetic approach (MA) for developing insights about the process and relational dynamics of ICT projects in complex contexts - in this case, the Kenyan public sector across a 40-plus year time line. As the authors point out, Archer conceived MA as the practical complement of CR philosophy, supplying an explanatory methodology grounded in an adequate social ontology and of practical use for analysts. A great strength of the paper is that MA is used in an in-depth study to reveal over a long time line the processes and mechanisms that explain how the ICT for development trajectory emerged from the interplay of interactions at different levels of players in global, national, public, private, third sector, and civil society institutions and organizations. Njihia and Merali found that MA made it incumbent on them to look for deep systemic generative causal mechanisms and to account for the import and impact of the broader context. Archer's analytic apparatus enabled separation of the parts from the whole, the analysis of time and temporality in processes of transformation, and the role of network structures and dynamics in explaining ICT-related change. The authors also see the adoption of CR methodology and its emancipatory ethos as potentially changing how ICT4D studies are conducted, including under what assumptions they are pursued.

In "The Generative Mechanisms of Digital Infrastructure Evolution," Henfridsson and Bygstadt contribute a major study of the important and neglected area of digital infrastructure in contemporary organizations. Their paper deals with the research question: Which mechanism contingently causes digital infrastructure evolution? The researchers choose critical realism as an intellectual structure for its emphasis on generative mechanisms, because there has been all too little research on digital infrastructure geared toward developing a comprehensive understanding of the range of contingencies of causal structures in its evolution. Henfridsson and Bygstad also develop a configurational perspective by using a multimethod research design This involved a fouryear in-depth case study of a new entrant airline in order to identify mechanisms with the power to cause digital structure evolution. The paper uncovers two conditions that provided a powerful environment for digital infrastructure evolution: an enabling, service-oriented architecture and an open, entrepreneurial culture. But while these conditions triggered the evolution, the analysis uncovered three mechanisms behind the successful evolution observed at the airline: the innovation mechanism, adoption mechanism, and scaling mechanism (AIS). The study is notable not least for its next step methodologically: a systematic collection and coding of 41 case studies from the research literature on digital infrastructure, 
with the coding scheme focusing on three elements of configuration, namely context, mechanisms, and outcome. They find multiple causal paths of digital infrastructure evolution, but, valuably, work through in detail the contingent arrangements that produce successful and unsuccessful outcomes.

Williams and Karahanna also tackle a big subject armed with critical realist concepts and methods. Their paper is titled "Causal Explanation in the Coordinating Process: A Critical Realist Case Study of Federated IT Governance Structures." Here, the researchers focus on a perennial issue in IS, that of effective IT governance structures. However, the study is unusual in tackling the very neglected, although critical, issue of coordination and how it is achieved. An immediate contribution is the discussion of coordination mechanisms and their role. A key product here is a conceptualization of the coordinating process based on a critical realist perspective. The researchers then carry out a comparative longitudinal case study of two coordinating efforts in a federated ITG structure. Their objective was to conduct a critical realist search for causal mechanisms. Using a logic employing deductive, inductive, and retroductive elements, they identify two causal mechanisms - consensus making and unit aligning - that help to explain the coordinating process and outcomes observed in the two efforts. Because the case research is so rich, the authors are able also to develop a multilevel understanding of unit level and consensus-making coordinating as macromicro, micro-macro, and micro-micro level mechanisms. The paper also discusses complementarity with rational choice and power/politics theories as explanations.

The final paper selected for this special issue that we will discuss provides a highly interesting, CR-informed case application at the country and regional levels. In "Explaining Broadband Adoption in Rural Australia: Modes of Reflexivity and the Morphogenetic Approach," Dobson, Jackson, and Gengatharen use critical realism as an "under-laborer" to help examine the complex reality of rural adoption for communities and small business in the regions. In this paper, a study of the development and adoption of the Australian National Broadband Network takes the foreground. However, Danermark et al. (2002) propose a critical realist method involving six stages in explanatory research and this is used to guide the methodological development, while Archer's morphogenetic model provides the basic social theory for examining the intimate relationship of broadband and use with rural social dynamics. The paper is notable for using Archer's more recent work on reflexivity to structure and inform the analysis. The paper demonstrates well how Danermark et al. can be applied, in particular the central abstract processes of analytical resolution, abduction/theoretical description, retroduction, and comparison with different theories. The study is also rare in IS in using Archer's later publications to address how an agent's internal reflexivity ("the internal conversation") interacts with imposing structural conditions to potentially create change. Archer suggests four modes of reflexivity - communicative, autonomous, meta, and fractured - and the study shows how these can play out in specific contexts, identifying agency as having an important role in the mechanism by which agents interact with relevant cultural and socio-cultural structures in morphogenetic or morphostatic sequences as agents adopt broadband or not.

\section{Conclusion}

We are grateful to the team of AEs who not only did a fine job of finding reviewers but also supplied authors with detailed and constructive reports. Much of what makes this a successful contribution to on-going works is due to their input, and we thank Michael Cuellar, Philip Dobson, Donald Hislop, Ivan Horrocks, Duane Truex, Olga Volkoff, Clay Williams, and Donald Wynn. It will be noted that some of these people also submitted articles; we ensured that there was strict separation between their roles. We received 30 submissions, which was very pleasing. This is, of course, an emerging and developing area of interest, and so it is perhaps not surprising that some familiar names appear. By the same token, however, we welcome some new voices to the conversation and we are encouraged by some new connections that are made by our contributors. We hope that our readers also find value in the work presented here and that it might encourage them to explore further the rich resources offered by critical realism.

\section{References}

Ackroyd, S., and Fleetwood, S. 2000. Realist Perspectives on Management and Organisations, London: Routledge.

Allen, D. K., Brown, A., Karanasios, S., and Norman, A. 2013. "How Should Technology-Mediated Organizational Change Be Explained? A Comparison of the Contributions of Critical Realism and Activity Theory," MIS Quarterly (37:3), pp. 835-854.

Archer, M. 1979. Social Origins of Educational Systems, London: Sage Publications.

Archer, M. 1988. Culture and Agency, Cambridge: Cambridge University Press.

Archer, M. 1995. Realist Social Theory: The Morphogenetic Approach, Cambridge, UK: Cambridge University Press.

Archer, M. 2000. Being Human: The Problem of Agency, Cambridge, UK: Cambridge University Press.

Archer, M. 2003. Structure, Agency and the Internal Conversation, Cambridge, UK: Cambridge University Press.

Archer, M. 2007. Making Our Way through the World: Human Reflexivity and Social Mobility, Cambridge, UK: Cambridge University Press. 
Archer, M. 2012. The Reflexive Imperative in Late Modernity, Cambridge, UK: Cambridge University Press.

Archer, M., Bhaskar, R., Collier, A., Lawson, T., and Norrie, A. (Eds.). 1998. Critical Realism: Essential Readings, London: Routledge.

Bhaskar, R. 1978. A Realist Theory of Science, Hemel Hempstead: Harvester.

Bhaskar, R. 1979. The Possibility of Naturalism, Sussex, UK: Harvester Press.

Bhaskar, R. 1986. Scientific Realism and Human Emancipation, London: Verso.

Bhaskar, R. 1989. Reclaiming Reality, London: Verso.

Bhaskar, R. 1993. Dialectic: The Pulse of Freedom, London: Verso.

Danermark, B., Ekstrom, M., Jakobsen, L., and Karlsson, J. 2002. Explaining Society: Critical Realism in the Social Sciences, London: Routledge.

Dobson, P. 2001. "The Philosophy of Critical Realism-An Opportunity for Information Systems Research," Information Systems Frontiers (3:2), pp. 199-210.

Dobson, P., Jackson, P., and Gengartharen, D. 2013. "Explaining Broadband Adoption in Rural Australia: Modes of Reflexivity and the Morphogenetic Approach," MIS Quarterly (37:3), pp. 965-991.

Elder-Vass, D. 2008. "Searching for Realism, Structure and Agency in Actor Network Theory," The British Journal of Sociology (59:3), pp. 455-473.

Faulkner, P., and Runde, J. 2013. "Technological Objects, Social Positions, and the Transformational Model of Social Activity," MIS Quarterly (37:3), pp. 803-818.

Fleetwood, S. (Ed.) 1999. Critical Realism in Economics: Development and Debate, London: Routledge.

Fleetwood, S., and Ackroyd, S. (Eds.). 2004. Critical Realist Applications in Organisation and Management Studies, London: Routledge.

Giddens, A. 1984. The Constitution of Society, Cambridge, UK: Polity Press.

Henfridsson, O., and Bygstad, B. 2013. "The Generative Mechanisms of Digital Infrastructure Evolution," MIS Quarterly (37:3), pp. 907-931.

Illari, P., and Williamson, J. (Eds.). 2011. Causality in the Sciences, Oxford, UK: Oxford University Press.

Ilyenkov, E. 1977. Dialectical Logic: Essays on its Theory and History, Moscow: Progress.

Lawson, T. 1997. Economics and Reality, London: Routledge.

Leonardi, P. M., and Barley, S. R. 2008. "Materiality and Change: Challenges to Building Better Theory About Technology and Organizing," Information and Organization (18:3), pp. 159-176.

Longshore Smith, M. 2006. "Overcoming Theory-Practice Inconsistencies: Critical Realism and Information Systems Research," Information and Organization (16:3), pp. 191-211.

Mingers, J. 2001. “Combining Is Research Methods: Towards a Pluralist Methodology," Information Systems Research (12:3), pp. 240-259.

Mingers, J. 2004a. "Can Social Systems Be Autopoietic? Bhaskar's and Giddens' Social Theories," Journal for the Theory of Social Behaviour (34:4), pp. 403-426.
Mingers, J. 2004b. "Re-Establishing the Real: Critical Realism and Information Systems Research," in Social Theory and Philosophy for Information Systems, J. Mingers and L. Willcocks (eds.), London: Wiley, pp. 372-406.

Mingers, J. 2006. "A Critique of Statistical Modelling in Management Science from a Critical Realist Perspective: Its Role Within Multimethodology," Journal Operational Research Society (55:2), pp. 202-219.

Mutch, A. 2010a. "Organizational Use of Information and Communication Technology and its Impact on Reflexivity," in Conversations About Reflexivity, M. Archer (ed.), London: Routledge.

Mutch, A. 2010b. "Technology, Organization and Structure-A Morphogenetic Approach," Organization Science (21:2), pp. 507-520.

Njihia, J. M., and Merali, Y. 2013. "The Broader Context for ICT4D Projects: A Morphogenetic Analysis," MIS Quarterly (37:3), pp. 881-905.

Olsen, W., and Morgan, J. 2005. "A Critical Epistemology of Analytical Statistics: Addressing the Sceptical Realist," Journal for the Theory of Social Behaviour (35:3), pp. 255-284.

Orlikowski, W. 2000. "Using Technology and Constituting Structures: A Practice Lens for Studying Technology in Organizations," Organization Science (11:4), pp. 404-428.

Orlikowski, W., and Scott, S. 2008. "Sociomateriality: Challenging the Separation of Technology, Work and Organization," Academy of Management Annals (2:1), pp. 433-474.

Peirce, C. 1931-1958. Collected Papers of Charles Sanders Peirce (8 Volumes), Cambridge, MA: Harvard University Press.

Pratschke, J. 2003. "Realistic Models? Critical Realism and Statistical Models in the Social Sciences," Philosophica (71), pp. 13-38.

Sayer, A. 2000. Realism and Social Science, London: Sage Publications.

Venkatesh, V., Brown, S., and Bala, H. 2013. "Bridging the Qualitative-Quantitative Divide: Guidelines for Conducting Mixed Methods in Information Systems," MIS Quarterly (37:1), pp. 21-54.

Volkoff, O., and Strong, D. M. 2013. "Critical Realism and Affordances: Theorizing IT-Associated Organizational Change Processes," MIS Quarterly (37:3), pp. 819-834.

Volkoff, O., Strong, D. M., and Elmes, M. B. 2007. "Technological Embeddedness and Organizational Change," Organization Science (18:5), pp. 832-848.

Williams, C. K., and Karahanna, E. 2013. "Causal Explanation in the Coordinating Process: A Critical Realist Case Study of Federated IT Governance Structures," MIS Quarterly (37:3), pp. 933-964.

Wittgenstein, L. 1958. Philosophical Investigations, Oxford, UK: Blackwell.

Wynn, D., and Williams, C. K. 2012. "Principles for Conducting Critical Realist Case Study Research in Information Systems," MIS Quarterly (36:3), pp. 787-810.

Zachariadis, M., Scott, S., and Barrett, M. 2013. "Methodological Implications of Critical Realism for Mixed-Methods Research," MIS Quarterly (37:3), pp. 855-879. 